\title{
Pattern of Valvular Involvement in Rheumatic Heart Disease (RHD) Patients attending Referral Cardiac Center in Nepal
}

\author{
Dr. M.B.KC, Dr. S.B.S. Kansakar, Dr. Y.K.D.Bhatta, Dr. R.Rajbhandari, \\ Dr. A, Maskey, Dr, D.Sharma, Dr, R. Malla, Dr. Y. Limbu, Dr. Rajbhandarl, \\ Dr, S.R. Regmi.
}

Rheumatic heart disease (RHD) is very common in developing countries. It is one of the commonest cardiac problems in Nepal. It is more common in rural areas than in the cities. We performed a retrospective study of RHD patients attending and undergoing echocardiography in Shahid Gangalal National Heart Centre (SGNHC) from January 2002 to December 2002. There were a total of 1843 RHD patients among which 787 (42.8\%) were males and 1056 (57.2\%) were females.

\begin{tabular}{|l|l|}
\hline Valves & Number (Percentage) \\
\hline MS+MR & $317(17.3 \%)$ \\
\hline MR & $294(15.9 \%)$ \\
\hline MS & $233(12.8 \% \%)$ \\
\hline MR+AR & $223(12.2 \%)$ \\
\hline MS+ MR+AR & $206(11.4 \%)$ \\
\hline AML/PML (Mitral valve) & $135(7.45 \%)$ \\
\hline MS+AR & $118(6.5 \%)$ \\
\hline MS+MR+AS+AR & $86(3.79 \%)$ \\
\hline MR+AS+AR & $58(3.36 \%)$ \\
\hline MS+AS+AR & $55(2.98 \%)$ \\
\hline AR & $49(2.68 \%)$ \\
\hline AS+AR & $28(1.74 \%)$ \\
\hline MS+MR+AS & $5(0.45 \%)$ \\
\hline MS+AS & $3(0.17 \%)$ \\
\hline AS & $3(0.17 \%)$ \\
\hline
\end{tabular}


Involvement of various valves was analyzed in isolation and in combination. The commonest lesion was a combination of mitral stenosis and mitral regurgitation (17.3 \%) followed by a combination of mitral regurgitation and aortic regurgitation (12.2\%). Rheumatic involvement of tricuspid and pulmonary valves was not seen. $33 \%$ patients showed rheumatic heart disease without hemodynamic alteration. Mitral Valve was seen to be involved more than aortic valve and when both mitral and aortic valves were taken into consideration, mitral regurgitation along with Aortic regurgitation (12.2\%) was found to be the commonest lesion. 